\title{
An Assessment of Network Learning in Higher Education: The Case of Mekelle University Undergraduate Students
}

\author{
Author: Nuru Seid Abidu \\ Lecturer, College of Social Sciences and Humanities, Raya University, PO box 92, Maichew, Tigray, Ethiopia \\ MA graduate in Educational Planning and Managemenet (Human Resource and Organizational Development \\ Stream),Addis Ababa University, Addis Ababa, Ethiopia(2010)
}

\begin{abstract}
The vision for higher education institutions described by the Ministry of Education (MoE) suggests a need for innovative instructional approaches consistent with current recommendations and reforms. This study explored the perceptions and understanding of department heads $(n=9)$, quality assurance officers $(n=2)$ and teachers $(n=9)$ who have been offered support/guidance for networks, undergraduate students $(n=80)$ who have been organized in Network learning and network leaders $(\mathrm{n}=16)$. These participants were from two colleges in Mekelle University (MU): College of Natural and Computational Sciences(CNCS) as well as College of Dry Land Agriculture and Natural Resources (CDLANR).The Network Learning is realized as a means to utilize the fundamentals of small group learning and that contribute to successful student learning as opposed to a more traditional small group learning approaches. To do this effect, a questionnaire having three parts was administered to student networks (network leaders) and Focused Group Discussion (FGD) carried out with faculty members of the two colleges in order to elicit in depth their beliefs and understandings about Network Learning, such as, what constitutes effective Network Learning, and how it works. While SPSS was inter alia be utilized to analyze quantitative data, descriptive approach under predetermined thematic topics was used to analyze qualitative data. The key findings were the following: (1) most teachers seemed to have positive attitude toward Networking Learning, yet their understanding of the basic components of small group learning such as student networks, was problematic; (2) Student Network leaders reported networks are not functioning well, and (3) The students expressed trust in teacher role during small group learning and have the confidence that network members comply with basic principle of small group learning.
\end{abstract}

Keywords: Student Network: A network consist of a team of five students that are linked in classroom setting to help each other for furthering learning.

Learning: Refers to multi-dimensional and multi-phase activity of students to acquire knowledge and skill.

DOI: $10.7176 / \mathrm{JEP} / 11-7-02$

Publication date:March $31^{\text {st }} 2020$

\section{Introduction}

Historically, small group learning dates back to the times of Jean Piaget (1971) and Lev Vygotsky (1962); it is not a new concept. Both Piaget and Vygotsky believed that students learn best when organized in small groups in way that trigger cognitive conflicts. With this basic assumption, small group learning has prominently been used for improving academic performance and achievement with little or no emphasis given to nonacademic matters that considerably affect student learning. Yet, this tradition is supported by local and global documents emerged recently. For example, the Higher Diploma Program (HDP) for Teacher Educators in its Handbook for Teacher Educators (Ministry of Education, 2004; 2007) has identified small groups as mainstay for cooperative and collaborative learning approaches with little or no attention given to nonacademic and ethical issues as they can boost or hinder to the best of student learning.

Small group learning, currently referred as Student Network Learning, has been introduced without exception to any public Higher Education Institution (HEI) in the nation. This small group learning differs significantly from the abovementioned types of small group. According to the Educational Development Army (EDA), in its guidelines, Educational Development Processes and Organizations (Ministry of Education, [MoE], 2013), nonacademic activities and other related matters should be treated with emphasis to ensure, among others things, effectual teaching and learning with understanding. As to this document, students who have been organized in network learning are engaged in goal setting, individual and network evaluation, treatment of student disciplinary issues, resource management, documentation of minutes and discussion activities, and competition as a subsequent result of cooperation and collaboration.

It is apparent therefore that the HEIs in Ethiopia are subjected to external and internal challenges with regard to EDA practice and implementation. While the government imposes pressure through the supervision of its regulatory bodies, the HEIs suffer challenge from faculty and staff as well as students as a result of hindrance in attitude and commitment towards EDA or lack of the relevant competency. Given this pressure and challenge, Mekelle University (MU) has become concerned about EDA practice and implementation as per government guidelines and directions, and thus delivered trainings that aimed at creating awareness and understanding of EDA 
fine points for both academic, and administrative and technical support wings as accompanied with comprehensive supervisions repeatedly. However, the problems and issues still remain. This article reports on the result of survey study on the practice and implementation of EDA in MU.

Student network learning refers to a small number of interdependent persons with complementary academic and nonacademic matters, who interact in order to acquire competency (knowledge, skills, attitudes, experience) and generate combined results (Silberman, 1996). In principle, student networks may be used in any discipline without any exclusion, either as separated activities in traditional teaching or by integrating them into more innovative methodologies, such as work-based learning, independent learning, active learning or student-centered learning, or problem-based learning. Thus, student network learning, which is the smallest unit in EDA organizational structure, calls for support from broader EDA units (the forums and development teams) and other networks for its success remained the most important unit, but encumbered with challenge as can be diminished or eroded by teacher and student traditional attitudes, uneven level of teacher expertise, limited commitment, highly structured/rigid system, and various an anticipated factors and challenges.

This exploratory study on student network learning and its processes at MU, therefore, aims at answering the following research questions:

1. To what extent do individual members of a network comply with basic principles of network/small group learning?

2. What is the evaluation of network leaders toward the proper functioning of networks?

3. What is the perception of network members toward teacher's role during network discussion?

4. What is the degree to which teachers/instructors practice the fundamentals of networks or small group learning?

\section{THEORETICAL FRAMEWORK}

\section{Meaning and Description of Network Learning}

What Is Network Learning? Educators and researchers who engaged in the enterprise of education have been employed diverse terminology to describe the idea "a small number of interdependent persons with complementary skills, who interact in order to acquire competency and generate combined results". The synonymous terminologies include: small group learning (MoE, 2004; 2007), peer learning (Falchikov, 2001), team learning (Oakley et al, 2004) and student network learning (MoE, 2013). For the purpose of this study, Network learning is used to describe small group learning involving 5 individuals of diversity in terms of ability, gender, ethnicity, social skills, physical attributes, and other parameters.

To answer the question "What is Network Learning?" it seems paramount importance to commence from the description of a "Network" itself. The term appears to have strong notion compared to the interchangeably used terminologies such as: team, small group, and peers. It involves exceeding dimensions than features describing teams, small cooperative groups and peers including the following: (1) having a shared collective identity, (2) have common goals, (3) are independent in terms of their assigned tasks or outcomes, (4) have distinctive roles within the group, (5) are part of a larger organizational context that influences their work and that they in turn can influence (Hughes \& Jones, 2011, p.54), and (6) organize and document activities to inform accomplishments. Weinstein et al (2013) as well as Weldeana et al, (2011) support this viewpoint of small group learning.

What is additional in networks is that there is a strong bond within and with other network members based on cooperative and collaborative approaches to minimize ability gaps between and among students as well as in ameliorating issues of disruptive or undesirable student behaviors that hinder student learning by creating a conducive learning environment.

\section{Why Networking Learning in Higher Education}

Many teachers and the high achieving students echoed the unfounded feeling that the less able and poorer students in small group/network learning waste their times for nothing. Students learning in network have the opportunity to learn with and from each other within classrooms or across cohorts through negotiation and sharing of ideas (Falchikov, 2001).

The benefits of small group learning is much acknowledged in the works of Jean Piaget $(1971 ; 1985)$ and Lev Vygotsky $(1962 ; 1978)$; it not unique to recent recommendations and reform agendas. Both Piaget and Vygotsky begin to describe the benefit of small group learning from the viewpoint of cognitive conflict, which means identifying ones "intellectual gap" or "a perpetual state in which one notices the discrepancy between one's cognitive structure and the environment as an individual learner or in comparison to others" (Lee, 2003; Weldeana and Tewolde, 2013). When students in network learning are exposed to interaction, they will be influenced by members in ways that result in the development of cognitive or intellectual skills or to shift their knowledge and understanding to enhanced levels.

Broadly speaking, Piaget believed that the co-operation between members is liable to boost real exchange of thoughts and discussions that result in critical attitude of mind, objectivity and discursive reflections. Vygotsky even went farther and suggested the irreplaceable role of competent adults or peers in uplifting ones knowledge 
and skills. To that end, he strongly argued that when one receives apposite assistance from a competent adult or from capable peers, both the individual's power of reflective thinking and cognitive development will heighten rapidly. The work of Oakley et al (2004, P.9) as quoted below elaborates the benefits of small group learning where no exception can be made to student networks:

compared to students taught traditionally, students taught in manner that incorporates small-group learning achieve higher grades, learn at deeper level, retain information longer, are less likely to drop out of school, acquire greater communication and teamwork skills, and gain a better understanding of the environment in which they will be working as professionals.

Marin-Garcia and Lloret (2008) also asserted that students in small groups engaged in active methodologies are likely to develop interpersonal skills frequently required by the labor market including communication, teamwork, group problem-solving, leadership, negotiation and time management as well as improved academic performance, the motivation and interest to learn and their attitudes toward learning. Sergi (2007) adds a relevant component of the benefit of small group learning not mentioned by many authors-that students involved in small group interactions including network learning have the opportunity to multicultural experiences. In their review of literature, Weldeana, et al. (2011) also listed multifaceted benefits of small group learning such as student networks learning. These include the following: improves the learning of academic content and promotes higher level thinking skills; provides students with the opportunity to think logically and creatively; fosters students' achievement and improves their ability solve problems; improves students' strategies for acquiring information; develops personal and social skills; boosts students' self-esteem; improves students' ability to work with others during learning; helps students experience self-reliance; increases gender relations; and allows students' own decision-making. These authors mentioned in this section, however, stressed that while these benefits are unlikely to occur within short periods of time, small groups encumbered with ineffectiveness or dysfunctional practices are likely to inferior to independent study in promoting learning and can lead to extreme nuisance and antipathy. Also, teachers can receive rewarding accomplishments when using student network learning because it is easier to assess groups than individuals, it is easier to cover more topics effectively and efficiently using small groups, and it fosters interaction whereby the negotiation and sharing of meanings is more practical as compared with ," teacher is telling and students are listening".

\section{The Role of the Teacher in Student Network Learning}

The role of the teacher cannot be compromised at any cost in managing small group learning such as student network learning, nor devalued when active learning methodologies are employed, because many wrongly think that most of the work is done by the students while the teacher keeps ideal position. However, this is not the case; the teacher is responsible in designing activities, guiding the processes, assess the processes properly, training the networks, sensitize students and prepare them to work in networks effectively. To that end, Oakley et al (2004, p.9) argue that "students are not born with the project management, time management, conflict resolution, and communication skills required for high performance teamwork." If assignments are to be given to small group learning in the form of networks, precise steps should be taken to support students learn those skills and to equip them to deal effectively with the resource and interpersonal problems that regularly arise in collaborative efforts. According to Marin-Garcia and Lloret (2008), the teacher has the responsibility to prevent the opportunist and parasite behavior patterns amongst the members of student network. Furthermore, the teacher has to deliver many things for student learning. In the first place, the teacher must realize that $\mathrm{s} / \mathrm{he}$ is a co-learner and thus be involved to motivate students, supervise activities, and supervise group processes. In the second place, students may be reluctant in small group learning; thus the teacher should give some time for training and practice as how to work in networks/small groups. In the third place, the teacher could take several hours to sensitize students through class dynamics and activities to enjoy and get the most out of student network learning. Fourth, the teacher should transparently declare the assessment criteria and how they are assessed individually as a member of a network for that product- what has to be handed in or submit such as reports, proposals, and oral presentations. Fifth, the teacher should inform clearly how they should work and how the team process. In the end, the teacher should budget some time to supervise networks by circulating around networks when activities are set in classrooms or setting a regular time to discuss and create continuous awareness as how to work with student networks. This has to be accompanied with providing the students with feedback on how they are performing and what could they improve. Teachers can support their works, using outstanding tools instrumental to network assessment as available in the literature (See, Hughes and Jones, 2011; Campion, 1999; Loughry, Ohland, and Moore, 2007).

\section{Fundamentals of Small Group Learning}

Organizing individual learners into groups having defined number of members is not suffice for meaningful student learning. Rather, there are components that make small group learning in the form of student networks effective with regard to performance and achievement. The prominent components that merit network learning a success will be discussed at some length in this section. 
The first of these is that define the organizational structure of student network learning. While Mickan and Rodger (2000) summarized the organizational structure of effective small groups including student networks is as one entertaining Clear purpose, appropriate culture, specified tasks, distinct roles, suitable leadership, relevant members, and adequate resources, Hopkins, (2002) identified comprehensive principles that underpin network learning as: positive interdependence, individual accountability, Face-to-face interaction, social skills, processing, and heterogeneous groups. With these commonalities among the scholarly descriptions of the organizational structure of small group learning, namely, the student networks; it is believed that they will be more functional and effective in accomplishing tasks and assignments as desired.

The second is group behaviors that are reflected by individual members that positively or negatively influence small group learning. What is important is that to answer the question "How can members with the limiting behaviors (e.g., dominator, doer, silent listener, diverger, whiner, and saboteur), be trained so that they would be members who contribute for the betterment of the network they are working in?" and "How can we build on deserving behaviors (facilitator, leader, problem solver, critical thinker etc) to facilitate student learning?" (MoE, 2004; 2007). According to the HDP Handbook (MoE, 2004; 2007), individuals with this unworthy behaviors can be trained so that a shift will be attained toward deserving behaviors for group success and attainment of the common goal. For Sergi (2007) as well, the unworthy group behaviors negatively influence the quality of a group's work. These group behaviors are frequently exposed overtly by group members: (a) who are indolent, (b) with disruptive behavior, (c) with poor ability, (d) who are overly ambitious, and (e) who fan the flames of conflict; thus, have to be corrected without delay.

The third is group interaction methods that enhance active learning (Leu, 2000; Kyriacou, 1998; MoE, 2004; 2007). Active and interactive processes in small group learning result in meaningful and long lasting changes in knowledge, understanding, and behavior. Active learning with regard to students is being intellectually active. By "intellectually active" is to mean students are expected to use information creatively and analytically-to describe information in their own words, compare information, analyze it, evaluate it and communicate about it in a variety of ways; thus teachers should design lessons and use group interaction methods that will require students in small groups to be intellectually active including the following: cooperative learning, peer teaching, jigsaw groups, crossover groups, goldfish bowl, hot seating, case study, and buzz groups.

Finally, as is the case in current educational workshops-professionals set clear and agreed ground rules prior to the commencement of the main agenda and put these ground rules into effect until it ends with success. These ground rules/group constitutions, when used properly have many advantages to earn. Firstly, it minimizes conflict among and between network members and enhances interaction as well as positive interdependence. Secondly, it compels the network and its members to focus on the agenda of the group in place of diverging unnecessarily. Thirdly, it enhances fair contribution among the members of the group in attaining the common goal of learning. Fourthly, it creates a ground of mutual respect among the network members. Fifthly, it creates conducive and enabling learning environment while discussing in small groups such as student networks. And finally, it guarantees safety for every individual while working as a network member. Hillier (2002, P.173-174) outlines some fundamental components of group constitution that can be used flexibly in a contract. These may include:

Confidentiality, giving constructive criticism, not attacking, or putting down others, expressing

feelings, honesty, listening to others, only one person to speak at a time, asking questions of clarity, right to keep silent, accepting the diversity of individuals within the groups, sexist, and racist language will not be tolerated, and inclusive language to be used throughout.

\section{METHODOLOGY}

\section{Subjects of the Study}

This survey study was conducted in two colleges at Mekelle University, CNCS and CDLANR in the time between February and May 2015 with a total of 16 student networks totaling 80 students as well as the leaders of these networks. Moreover, a total of 20 faculty members where 9 instructors, 9 department heads, and two college level quality assurance heads were also participated in the study. These participants including the students were randomly selected from both colleges to assure sheer chance. While $55(72.4 \%)$ of the student population was males the remaining participating students, $21(27.6 \%)$ were females. The frequency (percentage) by college is $48(63.2 \%)$ for CNCS and $28(36.8 \%)$ for CDLANR. The frequency (percentage) of students by department is given as displayed in Table 1. 
Table 1: Distribution of participants by department

\begin{tabular}{lll}
\hline Department & Frequency & Percent \\
\hline \hline Biology & 10 & 13.16 \\
Mathematics & 9 & 11.8 \\
Chemistry & 10 & 13.16 \\
Sport & 10 & 13.16 \\
Statistics & 9 & 11.8 \\
ARWS & 10 & 13.16 \\
RDAE & 10 & 13.16 \\
NREM & 8 & 10.53 \\
Total & 76 & 100 \\
\hline \hline
\end{tabular}

\section{Instruments of Data Collection}

This exploratory study used mixed methods-quantitative and qualitative research approaches. To do this effect, a questionnaire (Appendix 1) was administered for student networks and Focused Group Discussion (FGD) (Appendix 2) was conducted for faculty members (teachers, department heads, and quality assurance heads). The questionnaire had three sections: (1) student rating schedule for teacher's role in students' network discussion, (2) students' rating on network members' performance, and (3) network leaders' rating on network functioning and process. The student rating schedule for teachers' role in students' network discussion is a five-level Likert scale ranging from very low (1) to very high (5). Likewise, the students' rating on individual member contribution in network involved six major categories each containing 4 items stated affirmatively: positive interdependence, individual accountability, face-to-face interaction, social skills, processing, and heterogeneity. The rating involves a five level Likert Scale ranging from Strongly Disagree (1) Strongly Agree (5).The network leaders' rating on network functioning and process consisted of 11 items rated nominally as: usually(3), sometimes (2), and rarely (1). While the first sections of the questionnaire were adapted from Recee and Walker (2003), the third was adapted from Oakley et al (2004). The second, section of the questionnaire was developed by the researchers after consulting relevant literature in the field. Several modifications were made on these instruments to fit research objectives. The FGD format for both the faculty members was developed by the researchers after consulting much literature related to the topic of FGD, and how it is used.

\section{Reliability and Validity}

In order to measure the internal consistency of the instruments, an entire population Corrected Item-Total Correlation was calculated; the correlation between a given Task Value item and the sum score of the remaining items (r-CITC) and the Cronbach's Alpha when item is deleted $(\alpha-I D)$ calculated on 78 students from 9 departments in Mekelle University, Ethiopia. Whereas, the r-CITC was calculated for each item of the tools, the $\alpha$-ID was calculated for the total items for the tool in Table 2 and at the level of each of the six categories for the second tool in Table 3. The correlation between a given Task Value item and the sum score of the remaining items range from 0.460 to 0.732 for the tool in Table 1 and 0.516 to 0.805 for the tool in Table 2 in Appendix 1 .

This indicates that there is a strong, positive correlation between the scores on the one item and the combined score of the remaining. This is a technique to assess how well an item's score is internally consistent with composite scores from all other items in that list. If this correlation is weak, $\mathrm{r}-\mathrm{CITC}<0.30$ for item-analysis purposes, then that item should be removed.

On the other hand, while the $\alpha$-ID ranged from 0.876 to 0.891 for each of the 12 items in Table 2, the entire Cronbach's Alpha obtained is 0.892 . In this case, a drop of alpha oscillates in the range between 0.001 and 0.016 ; while there is no increase of alpha when a given Task Value item is removed. However, this drop of the alpha values is not significant and thus all items must be retained because each item appears to be useful and contribute to the overall reliability of Task Value. The Cronbach's Alpha when item is deleted ( $\alpha$-ID) and the Corrected ItemTotal Correlation (r-CITC) are provided for each item in Table 1.

Similarly, while the Cronbach's Alpha if item Deleted ranged from 0.679 to 0.876 for each of the 24 items in Table 3, the entire Cronbach's Alphas for: positive interdependence, individual Accountability, Face-to-Face Interaction, Social Skills, Processing, and Heterogeneity were obtained as $0.817,0.755,0.846,0.837,0.834$, and 0.861 , respectively; thus, the drop of alpha ranges between 0.003 and 0.089 ; while there is one increase of alpha at 0.005 when a given Task Value item is removed. However, this drop or increase of the alpha values is not significant and thus all items must be maintained. The Cronbach's Alpha when item is deleted ( $\alpha$-ID) and the Corrected Item-Total Correlation (r-CITC) are provided for each item in Table 2 of appendix 1.

The Focused Group Discussion (FGD) format for both faculty members was also subjected to validity check. Thus, the instrument was subjected to content validity as it refers to the existence of sample questions in the FGD representing content, the relevant skills, or behaviors of the area of interest; that means if the items of the FGD 
format are pertinent, exhaustive, relevant, and representative of the construct intend to measure. In doing this effect, the same faculty members from IPS were enthusiastically carried out the job.

\section{Data Analysis}

Data was enumerated for student questionnaire and the statistical package STATA was inter alia used. For the Focused Group Discussion (FGD), categories and subcategories were determined a priori. The researchers asked questions turn by turn and cautiously attend if responses of the participants lie in any of the categories in general and their subcategories in particular. In the end, for both the quantitative and the qualitative data, descriptive analysis was made to elaborate the findings of the research.

\section{Procedures}

After instruments for data collection were developed and organized completely, the researchers communicated the two colleges to obtain permission to conduct research with regard to small group learning. Of course, permissions were obtained immediately without any delay and with the sense that we are on your side to see the final finding of this research. In doing this, college deans were informed the randomly selected departments, student networks, and their leaders for data collection. Moreover, they were also informed that college quality assurance officers are parts of this study.

Finally, questionnaires were administered for student networks and their network leaders in the first place and the faculty members including the department heads, instructors, and head of quality assurance offices were subjected to the Focused Group Discussion (FGD) in the second place.

\section{FINDINGS}

\section{A Teacher's Role in Network Discussion}

Data analysis displayed in Table 2 indicates that students have generally rated the instructors' role during network discussions as high in a rating scale ranging from very low (1) to very high (5). While 10 of the 12 items were rated as high ranged from 4.0 to 4.3 , the remaining four items were rated close to 4 from below, ranging from 3.6 to 3.9. While three items rated at means score of 4.3, (instructor clarifies discussion task, encouraged members to talk freely, encouraged describing experience), and other two items were rated at mean score of 4.1, teacher allowed popular and unpopular views to be expressed as well as teacher offer information and share own experience for the best of student learning. Also, respondents have been confirmed that teachers have initiated network members to enthusiastically involve during network discussions $\mathrm{m}=4.2$.

Though network members rated relatively good in the items: teacher listened without interruption $(\mathrm{m}=3.8)$, teacher entertained expressed views with respect $(\mathrm{m}=3.9)$, teacher encouraged interchanging of roles among network members $(\mathrm{m}=3.8)$, teacher demonstrated tolerance or did not irritate with particular views $(\mathrm{m}=3.6)$, and teacher did not impose or think his view as superior $(\mathrm{m}=4.0)$, there appears to offer some space to improve on these items.

Table 2: Student rating schedule for Instructor's role in network discussion

\begin{tabular}{|l|l|l|l|l|l|}
\hline Item & Obs & M & SD & Min & Max \\
\hline Teacher clarified discussion task. & 76 & 4.3 & 0.82 & 2 & 5 \\
\hline Teacher encouraged members to talk freely. & 76 & 4.3 & 0.97 & 1 & 5 \\
\hline Teacher listened without interruption. & 76 & 3.8 & 1.1 & 1 & 5 \\
\hline Teacher entertained expressed views with respect. & 76 & 3.9 & 1.1 & 1 & 5 \\
\hline Teacher encouraged describing experiences. & 76 & 4.3 & 1.0 & 1 & 5 \\
\hline Teacher initiated members' involvement. & 76 & 4.2 & 1.2 & 1 & 5 \\
\hline Teacher encouraged interchanging of roles. & 76 & 3.8 & 1.3 & 1 & 5 \\
\hline Teacher demonstrated tolerance with specific viewpoint. & 76 & 3.6 & 1.1 & 1 & 5 \\
\hline Teacher did not force own views. & 76 & 4.0 & 1.3 & 1 & 5 \\
\hline Teacher gave information/share experience. & 76 & 4.1 & 0.94 & 1 & 5 \\
\hline Teacher allowed views to be expressed. & 76 & 4.1 & 0.94 & 1 & 5 \\
\hline Teacher allowed to draw conclusion & 76 & 4.1 & 1.1 & 1 & 5 \\
\hline
\end{tabular}

\section{Network Members Characteristic against Underlying Principles}

In this section of the questionnaire, respondents were provided with 24 positively stated items four in each category. A five level Likert Scale ranging from strongly disagree (1) to strongly agree (5) was used. The majority of the network members believed they are connected in accomplishing a common goal, contributed their ideas and view points to the network, realize the success of the network as success of the individual members, and feel connected with other networks. Indeed, this is evidenced by the aggregate mean score in the positive interdependence category as 4.3. Similar sentiments were also observed in the category heterogeneity where individual network members 
appreciate diversity, respect network members, and show willingness to negotiate and compromise to the diversified viewpoints within members with a maximum score of 4.4 .

Further, data analysis depicted in Table 3 indicated that network members have similar feelings in the remaining four categories: social skills, individual accountability, face-to-face interaction and process with having aggregate mean of 4.2. In this regard, network members felt that networks are functioning well whereby individual members are taking turns during discussion, actively listen to others during discussion, obtain support from competent members, probe peers in order to foster communication, practice leadership roles, and engaged in decision making and conflict management. More explicitly, respondents confirmed that members were adhered to teacher's guide and directions, comply with teacher assessment procedures, target on the network's overall improvement, and value for teacher assessment of the network's collaborative efforts. This is also relatively high as the aggregate mean for processing is calculated to be 4.2 .

Yet, network members asserted that they work in close proximity to each other during network discussions, negotiate ideas and meanings seating in round tables, avail themselves for face-to-face interactions, and show interest to do things lively with other network members at a mean score of 4.2 . With this relatively high mean score for face-to-face interaction of the network members, it seems worthwhile to build on these positive perceptions.

Table 3: Network members against underlying principles

\begin{tabular}{|l|l|l|l|l|l|}
\hline Category & OBS & M & SD & Min & Max \\
\hline Positive Interdependence & 75 & 4.3 & 0.94 & 1 & 5 \\
\hline Individual Accountability & 75 & 4.2 & 1.0 & 1 & 5 \\
\hline Social Skills & 74 & 4.2 & 0.98 & 1 & 5 \\
\hline Face-to-Face Interaction & 75 & 4.2 & 1.0 & 1 & 5 \\
\hline Processing & 75 & 4.2 & 1.1 & 1 & 5 \\
\hline Heterogeneity & 75 & 4.4 & 0.91 & 1 & 5 \\
\hline
\end{tabular}

Features of Network Functioning and Processing

Network leaders were asked to complete an 11-item questionnaire involving a three level scale, rarely (1), sometimes (2), and usually (3). As is disclosed in Table 4, network leaders testified that most network members experience the network process and functioning occasionally in most items, while in some likely to happen usually, and in one of the 11 items, there happens rarely.

It happens every so often that network members begin meetings 5-15 minutes late $(\mathrm{m}=2.2)$, arrive late, leave early, or never show up at all $(\mathrm{m}=2.4)$, have a vague notion or agenda $(\mathrm{m}=2.1)$, are dominated by one or two members $(\mathrm{m}=1.9)$, did not show interest for meeting $(\mathrm{m}=2.0)$, show limited interest to resolve issues $(\mathrm{m}=2.4)$, and rely on an individual or individuals who end up doing the majority of the work $(\mathrm{m}=1.7)$. As most of the behaviors described so far are undesirable and need improvement towards progressive positions, every effort has to be exerted so that networks can function properly.

As witnessed by the network leaders, network members prepare poorly for meetings regularly $(\mathrm{m}=2.6)$, constantly interrupt each other or talk in pairs $(\mathrm{m}=2.7)$, and fail complete assignments on time or completed poorly $(\mathrm{m}=2.8)$. This result seems frustrating for the reason that these are the major activities of the network meeting at large. In the end, network leaders evidenced that network members and networks rarely develop action plan for their activities; thus lack clarity with regard what the next step is and who is responsible for performing it.

Table 3: Network functioning with regard to meeting

\begin{tabular}{|l|l|l|l|l|l|}
\hline Network Functioning Activities: NW members & OBS & M & SD & Min & Max \\
\hline begin meeting 5-15 minutes late. & 16 & 2.2 & 0.59 & 1 & 3 \\
\hline arrive late, leave early, or never show up. & 16 & 2.4 & 0.58 & 1 & 3 \\
\hline have a vague notion/agenda. & 16 & 2.1 & 0.71 & 1 & 3 \\
\hline are dominated by one or two members. & 16 & 1.9 & 0.99 & 1 & 3 \\
\hline poorly prepared for meeting. & 16 & 2.6 & 0.59 & 1 & 3 \\
\hline did not show interest for meeting. & 16 & 2.0 & 0.61 & 1 & 3 \\
\hline constantly interrupt each other or talk in pairs & 16 & 2.7 & 0.52 & 1 & 3 \\
\hline show limited interest to resolve issues. & 16 & 2.4 & 0.59 & 1 & 3 \\
\hline develop action plan, thus clear. & 16 & 1.4 & 0.54 & 1 & 3 \\
\hline rely on individual(s) who end up majority of work. & 16 & 1.7 & 0.59 & 1 & 3 \\
\hline fail to complete assignments on time or are completed poorly. & 16 & 2.8 & 0.50 & 1 & 3 \\
\hline
\end{tabular}

Faculty Perspectives on the Fundamentals of Network Learning

20 faculty members participated in a Focused Group Discussions (FGD), to assess if they would have been well acquainted with the fundamentals of small group learning such as student networks. 


\section{Phases of Teacher Behavior in Network/Small Group Learning}

Two questions were asked consecutively: one that addresses instructors' understanding of phases of teacher behavior in small group learning and how each phase is implemented. As usually is the case, most teachers tend to attend the traditional way of lesson presentation in formal teaching styles. However, current educational materials that encourage the informal teaching style include phases of teacher behavior in network learning/small group learning involves five phases in five corresponding teacher behaviors (BEST, 2000). The complete phase is disclosed in Table 5 .

Table 5: The phases of teacher behavior in small group learning activities

\begin{tabular}{l|l}
\hline Phase & Teacher behavior \\
\hline Phase 1: Provides objectives & $\begin{array}{l}\text { Teacher goes over objectives for the lesson and establishes learning set. } \\
\text { Phase 2: Presents information }\end{array}$ \\
$\begin{array}{l}\text { Phase 3: Organizes students in presents information to students either through verbal } \\
\text { learning teams } \\
\text { Phase 4: Tests }\end{array}$ & $\begin{array}{l}\text { Teacher explains to students how to form learning teams; helps groups } \\
\text { make efficient transition. } \\
\text { Teachers tests knowledge of learning materials; organizes groups, } \\
\text { presents results of their work } \\
\text { Teacher finds ways to recognize both individual and group-effort and } \\
\text { achievement. }\end{array}$ \\
\hline
\end{tabular}

\section{Group Behaviors and their Impact on Student Learning}

The summary questions that were asked to participating faculty members were: to describe group behaviors, how these behaviors affect positively or negatively on student learning, and what can be done so that they can be used for the best of student learning. However, nearly all responses were not relevant to the point of discussion and they had not any idea of what these group behaviors are, how they impact student learning and as what can be done with these behaviors so that students learn with the best of their potential.

However, the Higher Diploma Program (HDP) in its Handbook for Teacher Educator, (MoE, 2004; 2007) describes the group behaviors that are worthy developing and these undeserving to student learning. As to the, Handbook, the unworthy behaviors can restrain group as well as individual success, can aggravate group conflicts, and weaken group interaction and relationships, thus suggest to train individuals with these behaviors not fit for small group learning. What is worth mentioning is that undeserving behaviors can be modified through proper training and corrective treatments to shift them towards the progressive and deserving behaviors.

\section{Group Interaction Methods that Enhance Active Learning}

Faculty members who participated in the FGD were asked to explain some of the group interaction methods that enhance active learning as well as how and when these methods used. They were unable to mention a single of the group interaction methods that enhance active learning; thus, either they lack the basic knowledge of interaction methods that enhance active learning or they lack the commitment to update their knowledge. However, many of the teachers claimed that it is "challenging to employ active learning methods in large group size" as is usually claimed in teacher professional trainings focused on active learning, and continuous assessment.

\section{Group Constitutions}

Two questions were asked: related to prevalently used group contracts in network learning and why they used these group contracts in case they were applied. The idea that group conflicts can be managed using group contracts, what is usually referred as group rules is not plausibly vivid for most teachers. Except possibly the traditionally practiced class management approaches practiced when students experience disruptive behaviors, the elements of group ground rules based scientific approach are little known.

\section{Criteria for Assessing Small Group Processes}

Respondents were subjected to three questions as how to assess group processing and individual contributions. These include: "a successful way to assess group and individual contributions to small group learning", "extent that individual contributions for group success in small group learning/network learning", and "good experience that could be shared in managing group assessments or individual contributions". Most of the responses of the participants clustered around one single or two topics, "Selecting an individual member of a network to present a group assignment or project randomly" or "Asking questions to some of the members randomly", which actually are of the same.

There are missing awareness and acquaintance of the scientific approaches including "Frequency of participation", "Meeting deadlines", "Appropriate interpersonal communication", "Delegating/leading without dominating", "Accepting and assuming responsibilities", "Suitable handling of disputes", "Decision- 
making/group problem-solving", and "Creativity" for small group such as the network assessment and individual contributions among the group of teachers, in this regard, the university instructors.

\section{Underlying Principles in Small Group/Network Learning}

Similar sentiments were also observed when teachers were required to answer the questions related to "The major underlying principles that govern small group learning/ student network learning?" and "Explain each principle as what it means to the teachers to most of network learning?" Teachers' response is highly related to the traditional way of ordering and commanding students usually referred as "Do this and not do that". They are not based on scientific knowledge of the underlying principles enlisted in the literature: "Positive interdependence", "Individual accountability", "Face-to-face interaction", "Social skills", "Processing", and "Heterogeneity".

Even some appreciate group or network formation on individual interest, which is relevantly based on interested groups-entertaining the same ability groups, social background, gender and others. Heterogeneity is less appreciated which involve diversity in: culture, ethnic group, gender, religion, social background, and ability.

\section{Conclusion}

The findings of this research warrant several conclusions to draw and several recommendations to suggest in relation to the formulated research questions.

The first question was "To what extent do individual members of a network comply with basic principles of network/small group learning?" The majority of the network members believed that they are connected in accomplishing a common goal, contributed their ideas and view points to the network, realize the success of the network as success of the individual members, and feel connected with other networks. Similar opinions were also observed in the category heterogeneity where individual network members appreciate diversity, respect network members, and show willingness to negotiate and compromise to the diversified viewpoints within members.

Besides, network members felt that networks are functioning well whereby individual members are taking turns during discussion, actively listen to others during discussion, obtain support from competent members, probe peers in order to foster communication, practice leadership roles, and engaged in decision making and conflict management. In the same manner, respondents confirmed that members were adhered to teacher's guide and directions, comply with teacher assessment procedures, target on the network's overall improvement, and value for teacher assessment of the network's collaborative efforts. Still, network members asserted that they work in close proximity to each other during network discussions, negotiate ideas and meanings seating in round tables, avail themselves for face-to-face interactions, and show interest to do things lively with other network members with high mean scores. Thus, this seems great opportunity to build on network learning so that the quality of student learning will be ensured.

The second question was "What is the evaluation of network leaders toward the proper functioning of networks?" The study exposed that network members neither attend network functioning principles usually nor rarely in most cases. It happens every so often that network members begin meetings 5-15 minutes late, arrive late, leave early, or never show up at all, have a vague notion or agenda, are dominated by one or two members, did not show interest for meeting, show limited interest to resolve issues, rely on an individual or individuals who end up doing the majority of the work, prepare poorly for meetings regularly, constantly interrupt each other or talk in pairs, and fail to complete assignments on time or completed poorly. In the end, network leaders evidenced that network members and networks rarely develop action plan for their activities; thus lack clarity with regard what the next step is and who is responsible for performing it. As most of the behaviors described so far are undesirable, every effort must be made to ensure improvements towards progressive positions for the proper functioning of networks.

The above two conclusions seem in contradiction to one another. While students in networks confirmed that they are in line with principles of student learning, the network leaders reversed this affirmation asserting that network members lack the basics of network functioning. Thus, further research has to be carried out so that this incongruities be settled between evidences testified by network leaders and the network members.

The third research question was "What is the perception of network members toward teacher's role during network discussion?"Data analysis and interpretation indicated that students in networks have generally rated the instructors' role during network discussions as high. This study, thus, disclosed that teachers clarify discussion tasks, encourage members to talk freely and describe experience, allow popular and unpopular views to be expressed, offer information, share own experience, initiate network members to enthusiastically involve during network discussions, listen without interruption, entertain expressed views with respect, encourage interchanging of roles among network members, demonstrate tolerance or did not irritate with particular views, and did not impose or think their view as superior for the best of student learning.

The fourth question was "What is the degree to which teachers/instructors practice the fundamentals of network/small group learning?" Qualitative data based on the FGD with faculty members (instructors, department heads and quality assurance officers) has been unveiled that teachers lack basic components of network/small 
group learning. To put it explicitly, teachers show little demonstration of the knowledge and acquaintance of the phases of teacher behavior, group behaviors that facilitate or hinder network/small group learning, group interaction methods that enhance active learning, group constitutions that lighten group conflicts, and the underlying principles that govern small group learning.

However, the last two conclusions demonstrate inconsistency to one another. While students in networks confirm teachers are good at playing their roles in offer support during network discussion, the qualitative analysis based on the FGD indicated that teachers fail to demonstrate the basic components helpful in network learning. This has to be researched because it seems somewhat unrealistic.

\section{References}

Campion, M. A., Medsker, G. J., and Higgs, A. C. "Relations Between Work Group Characteristics and Effectiveness: Implications for Designing Effective Work Groups.” Personnel Psychology, 1993, 46, 823850.

Cano Fernándeza, J. L., Lópeza, I. L., Rubioa, R. R., and Marco, F. G. (2009). An assessment of behavioral variables implied in teamwork: an experience with engineering students of Zaragoza University. European Journal of Engineering Education, 0(0),1-10.

Falchikov, N. (2001). Learning Together: Peer Tutoring in Higher Education. RoutledgeFalmer.

Hopkins, D. 2002. A Teacher's Guide to Classroom Research. $3^{\text {rd }}$ ed. London, McGraw-Hill Education: Open University Press.

Hughes, R.L. and Jones, S. K.(2o11). Developing and Assessing College Student Teamwork Skills. New Directions for Institutional Research, 149:53-64, DOI: 10.1002/ir.

Kyriacou, C. 1998. Essential Teaching Skills. 2nd ed. Cheltenham, UK: Nelson Thornes.

Loughry, M. L., Ohland, M. W., and Moore, D. D. "Development of a Theory-Based Assessment of Team Member Effectiveness." Educational and Psychological Measurement, 2007, 67(3), 505-524.

Marin-Garcia. J.A., And Lloret. J. (2008). Improving Teamwork with University Engineering Students. The Effect of an Assessment Method to Prevent Shirking. Wseas Transactions On Advances In Engineering Education, 1(5): 1-11.

Mickan, S., And Rodger S. (2000). Characteristics of effective teams: a literature review. Australian Health Review, 23(3): 201-208.

Ministry of Education (MoE, 2004). Higher Diploma Programme for Teacher Educators: Handbook. Addis Ababa, Ethiopia.

Ministry of Education (MoE, .2007). Higher Diploma Programme for Teacher Educators: Handbook. Addis Ababa, Ethiopia.

Oakley, B., Felder, R.M., Brent, R., and Elhajj, I. (2004). Turning Student Groups into Effective Teams. Journal of Student Centered Learning, 2(1): 9-34.

Piaget, J. (1971) Science of education and the psychology of the child, trans. D. Coltman, London: Longman.

Reece, I. \& Walker, S. (2003). Teaching, Training and Learning: A Practical Guide Incorporating FENTO Standards. Sunderland, Tyne and Wear: Business Education Limited.

Sergi, M. (2007). Evaluating short-term and long-term peer assessment of student teamwork. E-Journal of Business Education and Scholarship of Teaching, 1(1):41-58.

Silberman, M. (1996). Active Learning: 101 Strategies to Teach any Subject. Boston: Allyn and Bacon.

Vygotsky, L. S. (1962). Thought and language, Cambridge, MA: MIT Press.

Vygotsky, L. S. (1978). Mind in society, Cambridge, MA: Harvard University Press.

Weinstein, J., Morton, L. Taras, H. and Reznik, V. (2013). Teaching Teamwork to Law Students. Journal of Legal Education, 63(1): 37-64.

Weledeana, H. N., and Abraham, S., T. (2013). The effect an historical perspective on prospective teachers' beliefs on the learning of mathematics. Journal of Mathematics Teacher Education, 16(2): 17(4):303-330, December 19, 2013. Available online at: http://link.springer.com/article/10.1007\%2Fs10857-013-9266-Z

Weldeana, H. N.., Abraham, S. T, and Sbhatu, D. B. (2011). The effects of small group cooperative learning strategy on college students' performance of basic mathematics. Ethiopian Journal of Education, 30(1):6593. 